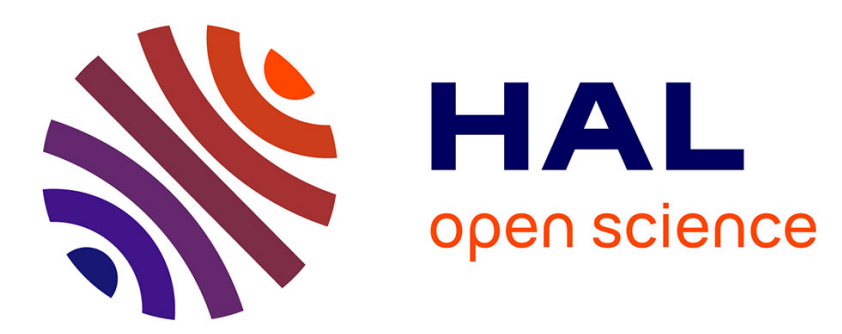

\title{
A combined action of pulmonary surfactant proteins SP-B and SP-C modulates permeability and dynamics of phospholipid membranes
}

Elisa Parra, Lara H. Moleiro, Ivan Lopez-Montero, Antonio Cruz, Francisco Monroy, Jesus Perez-Gil

\section{To cite this version:}

Elisa Parra, Lara H. Moleiro, Ivan Lopez-Montero, Antonio Cruz, Francisco Monroy, et al.. A combined action of pulmonary surfactant proteins SP-B and SP-C modulates permeability and dynamics of phospholipid membranes. Biochemical Journal, 2011, 438 (3), pp.555-564. 10.1042/BJ20110681. hal-00617332

\section{HAL Id: hal-00617332 \\ https://hal.science/hal-00617332}

Submitted on 27 Aug 2011

HAL is a multi-disciplinary open access archive for the deposit and dissemination of scientific research documents, whether they are published or not. The documents may come from teaching and research institutions in France or abroad, or from public or private research centers.
L'archive ouverte pluridisciplinaire HAL, est destinée au dépôt et à la diffusion de documents scientifiques de niveau recherche, publiés ou non, émanant des établissements d'enseignement et de recherche français ou étrangers, des laboratoires publics ou privés. 


\title{
A COMBINED ACTION OF PULMONARY SURFACTANT PROTEINS SP-B AND SP-C MODULATES PERMEABILITY AND DYNAMICS OF PHOSPHOLIPID MEMBRANES
}

\author{
Elisa Parra ${ }^{1}$, Lara H. Moleiro ${ }^{2}$, Ivan López-Montero ${ }^{2}$, Antonio Cruz ${ }^{1}$, Francisco \\ Monroy $^{2}$, Jesús Pérez-Gil $^{1 *}$ \\ From ${ }^{1}$ Dept. Bioquímica, Fac. Biología and ${ }^{2}$ Dept. Química Fisica, Fac. CC. Quimicas, \\ Universidad Complutense, Madrid, Spain
}

Running Head: SP-B and SP-C increase membrane permeability

*Address Correspondence to : Jesús Pérez-Gil Dept. Bioquimica, Fac. Biologia,

Universidad Complutense, Jose Antonio Novais 2, 28040 Madrid, Spain. Ph.: +34 91

3944994. Fax: +34 91 3944672. e-mail: jpg@bbm1.ucm.es

KEYWORDS: LIPID-PROTEIN INTERACTIONS, MEMBRANE PERMEABILITY, MEMBRANE PORES, LUNG SURFACTANT, MEMBRANE PROTEINS, MEMBRANE PERTURBATION 


\section{SYNOPSIS}

Proteins SP-B and SP-C are essential to promote formation of surface active films at the respiratory interface, but their mechanism of action is still under investigation. We have analyzed the effect of the proteins on the accessibility of native, quasi-native and model surfactant membranes to incorporation of fluorescent probes Nile Red (permeable) and FM®1-43 (impermeable) to membranes. We have also analyzed the effect of single or combined proteins on membrane permeation by the soluble fluorescent dye calcein. Fluorescence of FM 1-43 was always higher in membranes containing SP-B and/or SP-C than in protein-depleted membranes, in contrast to Nile Red, very similar in all the materials tested. SP-B and SP-C promoted probe partition with markedly different kinetics. On the other hand, physiological proportions of SP-B and SP-C made giant oligolamellar vesicles to incorporate instantaneously FM 1-43 from the external medium into apparently most of the membranes. In contrast, oligolamellar pure lipid vesicles appeared as mainly labelled in the outermost membrane layer. Pure lipidic vesicles were impermeable to calcein, while it permeated through membranes containing SP-B and/or SP-C. Vesicles containing only SP-B were stable but prone to vesicle-vesicle interactions, while those containing only SP-C were extremely dynamic, undergoing frequent fluctuations and ruptures. Differential structural effects of proteins on vesicles were confirmed by electron microscopy. These results suggest that SP-B and SP-C have different contributions to inter- and intra-membrane lipid dynamics, and that their combined action could provide unique effects to modulate structure and dynamics of pulmonary surfactant membranes and films. 


\section{INTRODUCTION}

Pulmonary surfactant, a membrane-based lipid-protein complex, is strictly required for breathing in pulmonated organisms. The presence of a surfactant layer at the respiratory surface is simultaneously responsible for biophysical stabilizing activities [1] and innate defence mechanisms [2]. The lack, deficiency or inactivation of the surfactant system is associated with severe respiratory disorders such as the Neonatal Respiratory Distress Syndrome (NRDS) in preterm babies [3] or the pulmonary dysfunction associated with Acute Respiratory Distress Syndrome (ARDS) in cases of lung injury [4].

In general terms, the composition of surfactant consists of about $90 \%$ lipids and $8-10 \%$ specific surfactant proteins, including two families: SP-A and SP-D, hydrophilic in nature, and SP-B and SP-C, both hydrophobic and membrane-associated [5]. The phospholipid fraction in surfactant is essentially responsible for its ability to reduce dramatically the surface tension at the air-liquid interface of the alveolar spaces. About $80 \%$ of surfactant by mass is composed of phosphatidylcholine (PC), about half of which is dipalmitoylphosphatidylcholine (DPPC) [6]. The acidic phospholipids phosphatidylglycerol and phosphatidylinositol represent $8-15 \%$ of the total surfactant phospholipid pool. Cholesterol is the main neutral lipid in surfactant, accounting for up to $8-10 \%$ by mass. The presence of proteins, specifically SP-B and SP-C, is absolutely necessary for interfacial adsorption, film stability and re-spreading activities of surfactant along the successive compression-expansion breathing cycles [7]. SP-B is thought to be the most important protein for respiratory physiology, as its lack or deficiency is associated with a lethal respiratory failure [8]. It has been previously shown that SP-B induces aggregation, fusion and lysis of phospholipid vesicles [9], and these activities have been associated with a putative role of SP-B to promote lipid transfer and membrane restructuration processes required to form the alveolar surface active films [10]. The role of SP-C in surfactant is not as crucial [11] but SP-C has been involved in membrane-membrane and membrane-interface contacts $[12,13]$. The combined action of both hydrophobic proteins is considered as responsible for the proper organization of functional membrane arrays in surfactant complexes.

The pulmonary surfactant system constitutes an excellent example of dynamic membrane polymorphism and how it controls some biological functions through specific lipid-lipid and lipid-protein interactions. Surfactant is assembled by alveolar type II pneumocytes in the form of tightly packed membranes stored in specialized organelles called lamellar bodies (LB) [14]. Once secreted, surfactant develops a membrane-based network that covers very rapidly and efficiently the whole alveolar surface. From surfactant assembly until its adsorption into the interface, several restructuration processes take place: membrane packing and unpacking in LBs, rearrangement of LB membranes into tubular myelin (TM), reorganization of surfactant membranes to form layers close to the air-water interface, and transfer of surface active lipid species from these complexes into the interface -and vice versa- during expansion-compression respiratory cycles (see review [7]). Surfactant proteins have a major role in facilitating all of these processes, but the elucidation of their precise molecular mechanism is a challenging task.

Different studies have suggested that pulmonary surfactant structures are composed of particularly dynamic membranes [15], and it is not clear whether those membranes are actually isolating different membrane or aqueous compartments. In the present study, we have analyzed the permeability and accessibility of native surfactant complexes and membranes reconstituted from different surfactant fractions to the incorporation of the membrane-sensitive fluorescent probes Nile Red and FM 1-43, able and unable, respectively, to permeate across phospholipid membranes. Particularly, we have evaluated the dependence 
of the accessibility of membranes and the environment sensed by the probes on the lipid and protein composition. Samples characterized in this study include complexes of native surfactant purified from porcine lungs and membranes reconstituted from whole surfactant organic extract or from partial fractions obtained by size-exclusion chromatography, which were compared to model lipid membranes. The effect of SP-B and SP-C on the permeability of model membranes has been also analyzed by fluorescence microscopy, through the reconstitution of POPC giant vesicles (GVs) in the absence or presence of the hydrophobic protein fraction of surfactant or purified SP-B or SP-C. 


\section{EXPERIMENTAL}

Materials - Native pulmonary surfactant materials were obtained from bronchoalveolar lavage of porcine lungs as described previously [16]. Organic extraction of purified surfactant and chromatographic separation in Sephadex LH-20 (Pharmacia, Uppsala, Sweden) allowed obtention of the hydrophobic protein fraction and the lipid surfactant fractions $[15,17]$. A subsequent chromatographic step in LH-60 yielded purification of SP-B and SP-C separately [17]. In general terms we obtain a proportion of around $0.8 \%$ SP-B and $1.1 \%$ SP-C with respect to phospholipid mass in the surfactant organic extract. Total phospholipid concentration in the different samples was determined by phosphorus analysis upon phospholipid mineralization [18]. Proteins and lipids were stored as chloroform/methanol 2:1 (v/v) solutions at $-20^{\circ} \mathrm{C}$. Protein solutions were routinely checked for purity by SDS-PAGE and quantified by amino acid analysis. 1-palmitoyl-2-oleyl-snglycero-3-phosphocholine (POPC) was purchased from Avanti Polar Lipids (Alabaster, AL, U.S.). Fluorescent dyes Nile Red and FM 1-43 were from Molecular Probes Inc. and calcein from Sigma Aldrich. Chloroform and methanol solvents, HPLC grade, were from Scharlau (Barcelona, Spain).

Vesicle preparation - Stock suspensions of native pulmonary surfactant were in $5 \mathrm{mM}$ Tris buffer, pH 7, containing $150 \mathrm{mM} \mathrm{NaCl}$. Multilamellar membrane suspensions (MLVs) of surfactant organic extract, the different surfactant lipid fractions or POPC supplemented or not with proteins SP-B and/or SP-C were prepared as follows. The appropiate amounts of proteins and lipids in chloroform/methanol 2:1 were mixed and the samples were then evaporated to dryness under nitrogen and 2 hours in a vacuum chamber to form a thin film, which was later resuspended at $45^{\circ} \mathrm{C}$ (for native materials) or $37^{\circ} \mathrm{C}$ (for POPC samples) in the desired final volume of $5 \mathrm{mM}$ Tris buffer, $\mathrm{pH} 7$, containing $150 \mathrm{mM} \mathrm{NaCl}$. Large unilamellar vesicles (LUVs) were prepared using a Mini-Extruder (Avanti Polar Lipids) with $10 \mathrm{~mm}$ diameter drain discs and $0,1 \mu \mathrm{m}$ diameter Nuclepore Track-Etch membranes (Whatman), passing the MLV suspension 11 times through the filters at $50^{\circ} \mathrm{C}$, in the case of native or quasi-native material, or $37^{\circ} \mathrm{C}$ for POPC samples with or without proteins. Small unilamellar vesicles (SUVs) were obtained by sonication (UP200, Hierlscher) of MLV suspensions $(0,6$ cycles, 65\% amplitude; 4 cycles of 2 minutes). LUV and SUV suspensions were used immediately.

Fluorescence spectroscopy with Nile Red and FM 1-43 - Fluorescent probes Nile Red or FM 1-43 were incorporated into the membrane suspensions at a final concentration of 3 and $2 \mu \mathrm{M}$, respectively, and incubated at room temperature protected from light for 30 minutes. To follow incorporation kinetics of FM 1-43, fluorescence emission was measured immediately after incorporation of the probe to the suspensions. Fluorescence emission spectra were registered in a spectrofluorimeter JASCO FP 6200 thermostated at $37^{\circ} \mathrm{C}$, using $5 \mathrm{~nm}$ excitation and $10 \mathrm{~nm}$ emission slitwidths. Nile Red fluorescence was monitored upon excitation at $548 \mathrm{~nm}$ and registering emission from 550 to $700 \mathrm{~nm}$, while samples labelled by FM 1-43 were measured exciting at $479 \mathrm{~nm}$ and recording emission from 500 to $650 \mathrm{~nm}$.

Electron microscopy - Droplets of a unilamellar suspension of POPC $(1 \mathrm{mg} / \mathrm{ml})$ with or without protein (full hydrophobic protein fraction, $1 \%$ SP-B or $1 \%$ SP-C by weight), prepared by extrusion, were placed on carbon-coated grids (Electron Microscopy Sciences, Hatfield, PA) for 4 minutes, stained with uranyl acetate for 40 seconds and observed under a JEOL JEM-1010 Transmission Electron Microscope.

Giant Vesicle Preparation - Giant Vesicles (GVs) made of POPC or POPC supplemented with $1 \% \mathrm{w} / \mathrm{w}$ of SP-B, SP-C or both were prepared following a slightly modified electroformation protocol [19]. Briefly, $10 \mu \mathrm{l}$ of $1 \mathrm{mg} / \mathrm{ml}$ lipid or lipid/protein solution in chloroform were spread in a indium tin oxide (ITO) coated glass slide (Sigma- 
Aldrich). The fabrication chamber is composed by two conductor glass slides separated by a Teflon spacer of $1 \mathrm{~mm}$. After organic solvent evaporation, the film was re-hydrated with a sucrose solution $(300 \mathrm{mM})$. The chamber was then connected to an A.C. power supply $(8 \mathrm{~Hz}$ and $1.1 \mathrm{~V}$ ) for 3 hours. Then, the frequency was decreased to $4 \mathrm{~Hz}$ for 30 minutes. The obtained vesicles had a spherical shape and a large proportion of oligolamellar vesicles were found. A volume of 25 microliters of the solution containing GVs was transferred from the fabrication chamber to the observation chamber containing $75 \mu \mathrm{l}$ of glucose solution (310 $\mathrm{mM})$.

Visualization of permeability of GVs to Calcein and FM 1-43 - In order to test the membrane permeability of GVs with different composition, giant vesicles were transferred to a glucose $(310 \mathrm{mM})$ solution containing $0.05 \mathrm{mM}$ of FM 1-43. In some experiments, the liposomes were incubated first in glucose containing $1 \mathrm{mM}$ of the bulk fluorescent marker calcein (Sigma-Aldrich, $494 \mathrm{~nm}$ excitation, $517 \mathrm{~nm}$ emission) and then diluted to glucose/FM 1-43. Calcein and FM 1-43 fluorescence was then monitored under a fluorescence microscope (Nikon Eclipse TE2000 using a 100W mercury lamp and FITC and Texas Red filter sets) and recorded with a cooled CCD camera (Nikon DS-1QM, $14 \mathrm{fps}, 1$ Mpixel). All GV suspensions were observed freshly made, preferently within the same day of preparation, although no significant changes were observed in permeability or morphology of the vesicles observed up to 48 hours after lipid hydration and vesicle preparation.

Reproducibility - When possible, data figures represent mean \pm standard error after averaging at least 3 different experiments, with at least two and often three entirely different surfactant and protein batches. In other cases, such as in GUV images, illustrative experiments are shown after repeating at least three experiments that exhibited consistent behaviour. 


\section{RESULTS}

To assess the effect of the presence of hydrophobic surfactant proteins SP-B and/or SP-C on the permeability of phospholipids membranes we have taken advantage of the fluorescent emission of two extrinsic probes. Nile Red is a phenoxazone dye that fluoresces intensely in organic solvents and membrane environments, but is completely quenched in aqueous media [20]. The emission properties of this probe depend strongly on the relative hydrophobicity of the surrounding environment. Phospholipid bilayers are highly permeable to Nile Red, so in principle it should label every single membrane in the samples. On the other hand, FM 1-43 is a styryl dye which is water soluble and also exhibits high affinity for lipid environments, although it doesn't translocate through membranes; consequently, it only labels the external leaflet of lipid vesicles. In addition, this probe only emits fluorescence once incorporated into membranes, as water molecules strongly quench its fluorescent emission [21].

Figure 1 compares the emission fluorescence intensity of Nile Red and FM 1-43 as a function of their incorporation into increasing concentrations of different lipid and lipid/protein suspensions, including native pulmonary surfactant complexes (NS) and multilamellar vesicles reconstituted from the whole surfactant organic extract (OE), the protein-free lipid fraction of surfactant (LF), surfactant lipid fraction depleted of cholesterol (LF $\Delta \mathrm{Chol}$ ) or the lipid fraction depleted of cholesterol but supplemented with the hydrophobic protein fraction of surfactant (LF $\Delta$ Chol+PF). For comparison, the fluorescence of the probes in increasing equivalent concentrations of multilamellar vesicles of POPC has been also determined. The effect of the presence of the different membrane materials on the fluorescence of the two probes is completely different. The fluorescence emission of Nile Red shows similar dependence on lipid concentration, within the experimental error, for the different materials tested up to concentrations around $200 \mu \mathrm{g} / \mathrm{ml}$ (left panel in Figure 1), indicating that all these materials exhibit similar accessibility to this membrane-permeable probe. For higher lipid amounts, some differences in the emission intensity of Nile Red become relevant, probably as a consequence of local differences in the polarity of the environment sensed by the probe. The probe shows higher emission in materials containing cholesterol and other neutral lipids (NS, OE and LF) than in membranes prepared from fractions depleted of cholesterol and, specially, in pure POPC membranes. This is probably a consequence of the well-known effect of cholesterol to seal membranes and reduce their level of hydration [22, 23]. The environment sensed by Nile Red in cholesterol-containing surfactant membranes would then be more dehydrated, and therefore more hydrophobic, than that in cholesterol-free bilayers, leading to a higher intensity of fluorescence emission. There are no apparent effects of the protein content on the fluorescence of this probe.

In contrast to Nile Red, the fluorescence emission of FM 1-43 is remarkably different in the different membranes studied (right panel of Figure 1). The probe showed around two-fold higher fluorescence in protein-containing membranes, i.e., those from native surfactant, its organic extract or its lipid fraction depleted of cholesterol but supplemented with SP-B and SP-C, than in those made of protein-free surfactant lipids. The fluorescence of the probe in surfactant lipid membranes was also substantially higher than measured in POPC bilayers. The presence of proteins SP-B and SP-C seems therefore important to provide lipid membranes with full accessibility to membrane-impermeable probes such as FM 1-43. Interestingly, Nile Red fluorescence increases rather linearly with phospholipid concentration while FM 1-43 fluorescence seems somehow to plateau, which could reflect differences in partition of the two probes between different surfactant lipid phases [15, 24], and therefore different levels of probe accumulation.

The differences in accessibility to FM 1-43 of the different membrane suspensions are probably manifested due to their multilamellar character. The outermost impermeable 
membranes would impede exposure of inner membranes to the probe. In Figure 2 we have compared probe accessibility of native surfactant membranes, membranes reconstituted from the whole surfactant organic extract, and model POPC bilayers when preparing suspensions with different lamellarity. As it could be expected, FM 1-43 produced higher fluorescence emission in unilamellar (LUV or SUV) vesicles than in multilamellar suspensions of POPC (right panel of Figure 2), as a consequence of the larger surface of membranes exposed to the externally added probe. In contrast, there are no apparent differences in the fluorescence emission of the probe partitioning in unilamellar or multilamellar suspensions of either native surfactant or its organic extract. Again this result points to a potential role of surfactant proteins to facilitate accessibility of the membrane-impermeable probe across different membranes.

To test whether the mere presence of SP-B and/or SP-C would be enough to facilitate partition of FM 1-43 across membranes, we have tested the effect of introducing surfactant proteins on the differences in probe accessibility when comparing unilamellar and multilamellar suspensions of simple POPC vesicles. Figure 3 compares fluorescence of FM 1-43 added to increasing concentrations of unilamellar or multilamellar suspensions of pure POPC in the absence or in the presence of hydrophobic surfactant proteins. Also, we have compared POPC membranes supplemented with the whole protein fraction of surfactant (SP$\mathrm{B}+\mathrm{SP}-\mathrm{C}$ at equivalent lipid-to-protein ratio to that obtained in the LH-20 chromatography) with membranes containing only $1 \%$ of purified SP-B or SP-C. Figure 3 (left panel) shows that the fluorescent emission of FM 1-43 is 4-fold higher in all protein-containing POPC MLVs than in pure phospholipid membranes, with small but consistent differences between the different protein-containing samples. The order of accessibility of membranes to the probe was always with respect to the protein content SP-B $>$ SP-B + SP-C $>$ SP-C. In contrast, the differences between protein-containing and protein-free POPC membranes with respect to the fluorescence of FM 1-43 were much reduced in unilamellar POPC suspensions (right panel of Figure 3).

To get further insight the differences between the effect of SP-B and SP-C to facilitate accessibility to FM 1-43 across multilamellar membrane arrays, we have compared in Figure 4 the kinetics of incorporation of the probe to different amounts of POPC multilamellar suspensions containing $0.25,1.0$ or $2.0 \%$ (protein to lipid by weight) of either purified SP-B or SP-C. Physiological proportions of these proteins are thought to be around $1 \%$ in native surfactant, but we wanted to test much lower subphysiological proportions to maximize kinetic differences. The kinetic of incorporation of FM 1-43 into the POPC membranes was significantly different when comparing the effect of SP-B and SP-C. In all the SP-Bcontaining membranes tested, the fluorescence emission intensity of the probe reached the maximum in less than 30 seconds since the addition of the dye, while in SP-C-containing samples, the emission increased gradually along the first 30 minutes, especially in the samples containing the lowest proportion of protein. Figure 5 compares the full dependence of maximal emission of FM 1-43 into POPC MLVs versus the protein density in the membranes for both SP-B and SP-C. Below $0.5 \%$ protein to lipid ratio (w/w), SP-B produced always higher fluorescence, hence better partition of the probe across membranes, than SP-C. The lower proportion of SP-B tested, $0.1 \%$ protein to lipid by weight, already produced maximal incorporation of FM 1-43 into POPC membranes, suggesting that SP-B is extremely efficient in facilitating permeability of this membrane-impermeable probe across bilayers.

The different behaviour of SP-B and SP-C with respect to the kinetics of incorporation of FM 1-43 across membranes suggests that intrinsic differences must exist between the mode and extent of perturbation by the two proteins of the structure and the permeability barrier of membranes. To get further insight the effect of the two proteins on the structure of the model membranes used in the present study, we have examined by electron microscopy the 
ultrastructure of POPC LUVs prepared in the absence or in the presence of the whole hydrophobic surfactant protein fraction or $1 \%$ by weight of purified SP-B or SP-C. Figure 6 shows representative images obtained by negative staining and transmission electron microscopy of these lipid and lipid/protein samples. Pure POPC suspensions contained a relatively homogeneous population of vesicles with homogeneous size, and presumably unilamellar character (image $\mathrm{A}$ in Figure 6), as well as the suspension of POPC supplemented with the mixture of SP-B and SP-C (image B). The POPC/SP-B suspension presented a high complexity, since it was totally made up by large, apparently multilamellar, membrane complexes with a diameter in the micrometer scale, in spite that they were originally extruded through $100 \mathrm{~nm}$ pores. The vesicles prepared with POPC plus $1 \%$ SP-C showed a higher level of aggregation than pure POPC vesicles, but it still consisted of unilamellar and oligolamellar vesicles with a more or less spherical shape.

In order to achieve a direct visualization of the effect of surfactant proteins on the membrane labelling by FM 1-43, in a more homogeneous and controlled membrane structural context, a series of fluorescence microscopy experiments have been carried out in which we have monitored the ability of the probe to label the different membranes in oligolamellar giant vesicles of POPC in the absence or presence of hydrophobic surfactant proteins. The large size of GVs prepared by electroformation allows their visualization under an optical microscope and the simultaneous examination of fluorescent probe partition and membrane macroscopic morphology. Figure 7 compares morphology and FM 1-43 labelling of pure POPC oligolamellar GVs and GVs formed from POPC supplemented with the hydrophobic surfactant protein fraction (PF) obtained after the LH-20 chromatography, at proportions mimicking lipid/protein ratios in surfactant organic extract. Two representative GVs of each sample are shown, exhibiting a clear oligolamellar structure under the optical microscope operated under phase contrast. Upon incubation with FM 1-43, pure POPC oligolamellar GVs were labelled only in the outermost layer (see images B and D in Figure 7). In contrast, exposure to the probe produced almost instantaneous labelling of every membrane in $\mathrm{POPC} / \mathrm{PF}$ vesicles (see images $\mathrm{F}$ and $\mathrm{H}$ in Figure 7). Similar experiments were carried out with GVs made of POPC supplemented with $1 \%$ by weight of either purified SP-B or SP-C. Surprisingly, the morphology of these giant liposomes containing only one of the surfactant proteins was substantially different to that of liposomes containing no protein or the full hydrophobic protein fraction. No clearly oligolamellar GVs could be found as made of the POPC/SP-B mixture. As illustrated in Figure 8, suspensions of POPC/SP-B vesicles were entirely composed of apparently unilamellar giant liposomes, with different sizes and a strong trend towards aggregation (see images A-D in Figure 8), which were fully labelled by FM 1-43. Suspensions of POPC/SP-C vesicles contained a large number of oligolamellar liposomes, but most of them became very unstable when observed under the microscope, showing a high tendency to distortion, rupture and reorganization. Figure 9 shows sequential frames taken from a video recording, illustrating the rupture of two giant oligolamellar vesicles: at first, the shape of both vesicles looked very irregular and their membranes started fluctuating; then, some membrane regions protruded and formed evaginations, which finally released smaller vesicles to the medium before becoming again spherical and stable. The complete recording is available as Additional Material (http://bbml.ucm.es/biomil/video/Video_Parra_JBC_1000_5MB.avi). We never saw such dynamical behaviour in pure lipidic vesicles or in liposomes containing SP-B.

To analyze further the effect of surfactant proteins on the permeability of membranes to polar molecules, we tested the ability of the fluorescent dye calcein to permeate through POPC liposomes in the absence or presence of the proteins. Figure 10 illustrates how pure POPC GVs can be incubated for several hours in a calcein solution without internalization of the dye. Vesicles appeared as dark spheres when observed under the blue light used to excite 
calcein (see image B in Figure 10). In contrast, incubation with calcein of vesicles of POPC supplemented with the hydrophobic surfactant protein fraction lead to the entrance of the dye. Image E in Figure 10 illustrates how calcein had entered into protein-containing POPC vesicles, showing even higher fluorescence that the liposome external medium. This indicates that equilibration of calcein concentration across the membrane takes some time once the concentration of the dye in the solution has been diluted down. Calcein could also permeate through POPC liposomes containing only SP-B or SP-C, but with an apparently different pattern than observed in liposomes containing the two proteins together. In the presence of either of the hydrophobic surfactant proteins no difference in fluorescence emission could be seen between the different compartments (see images $\mathrm{H}$ and $\mathrm{K}$ in Figure 10), indicating that calcein fluorescence equilibrated rapidly between the internal and external liposome compartments. Interestingly, images of calcein fluorescence in liposomes containing SP-B showed large segments of the membrane that were much darker than the aqueous calcein solution, as if calcein would be highly excluded from perimembranal regions. 


\section{DISCUSSION}

The ability of proteins SP-B and SP-C to introduce significant perturbations of structure and dynamics in surfactant phospholipid membranes has been largely documented. These perturbations have been mainly interpreted in the context of the role of the proteins to promote the structural transformations associated with pulmonary surfactant biogenesis, secretion and adsorption into the air-liquid interface. However, the intrinsic properties imparted by the particular lipid and protein composition to native-like pulmonary surfactant membranes have not been completely described. Little is known, for instance, with respect to the symmetric or asymmetric character of these membranes as they are assembled, or their permeability to polar solutes. We have tested the accessibility of membranes with different native-like or model lipid and protein composition to the membrane-fluorescent probe FM 143. This probe has been extensively used as a marker for lamellar body exocytosis, in order to obtain a direct visualization of pulmonary surfactant secretion in alveolar type II cells [25]. FM 1-43 stains intensely the whole lamellar body content immediately after the opening of the exocytotic fusion pore. This suggests the existence of a direct topological connection between all the lamellar body membranes and/or the inter-lamellar compartments. Our starting hypothesis was that the assemblies in which hydrophobic proteins SP-B and SP-C participate are involved in the free diffusion of probes like FM 1-43 across surfactant membranes once surfactant is released from type II pneumocytes.

The present data confirm that the hydrophobic proteins SP-B and SP-C are responsible to make phospholipid membranes highly permeable to polar molecules as it had been largely suspected. The ability of these proteins to alter the permeability barrier of phospholipid membranes had been reported, but mainly as a consequence of their interaction with membranes upon injection as concentrated solutions in organic solvents [26-28]. In the present work, we demonstrate that i) native surfactant membranes are indeed intrinsically permeable, ii) proteins SP-B and SP-C are responsible of the permeability properties of surfactant structures, and iii) hydrophobic surfactant proteins are by themselves able to make a simple phospholipid membrane highly permeable to both membrane and soluble probes. This could be consistent with the assembly in the membranes of some sort of proteinaceous or proteolipid pores, because the mere introduction of the hydrophobic surfactant proteins into a single lipid model membrane is enough to permeabilize it. Permeabilization of membranes by surfactant proteins produces as a consequence a rapid equilibration of molecules, which are intrinsically impermeable through pure lipid membranes, among the different compartments. We cannot discard that membrane-permeabilizing protein assemblies are not also promoting membrane-membrane contacts that would facilitate even further the rapid movement of polar and non-polar molecules through the different membranes and compartments. The effect of the proteins to facilitate lipid dynamics in large multilamellar arrays has been widely reported $[15,29]$. The present results introduce the effects on membrane permeability as an additional factor on surfactant dynamics.

Several evidences had already suggested a potential effect of surfactant proteins on membrane permeability. SP-B has been reported to promote association and fusion of phospholipids membranes [26, 30]. This SP-B-promoted fusion of lipid vesicles was described as "leaky", meaning that the protein-promoted merging of membrane compartments was always associated with leakage of at least part of the vesicle contents into the outer spaces. Our results suggest that leakage could not only occur at the fusion sites, but that membrane fusion and the subsequent transfer of the protein into the different lipid structures could end in the complete permeabilization of all the membranes. This permeabilization could be also behind the reported ability of hydrophobic surfactant proteins to permeabilize membranes to ions [31], a property that could not be explained and has not 
been characterized any further. Also, we and others had noticed the problems to encapsulate polar solutes into membrane vesicles made from pulmonary surfactant, a relevant technology in the context of drug-delivering strategies, but that may be more difficult to achieve than anticipated in the light of the present results. The difference in the kinetics of membrane probe equilibration is consistent with SP-B and SP-C promoting membrane permeability by different mechanisms. The almost instantaneous permeation of probes through phospholipid membranes containing minimal amounts of SP-B could be indicative of the protein forming true pores. The sequence of SP-B is homologous to saposins, a family of membraneassociated proteins that includes several recognized cytolysins and membrane-pore forming structures [32-34]. We propose that pore-like oligomeric SP-B assemblies could be at the same time responsible to establish membrane-membrane contacts and to facilitate rapid transfer of lipids and polar molecules between the contacted membrane compartments. In contrast, the kinetics of probe permeation by SP-C is much slower than that promoted by SP$\mathrm{B}$, and much more dependent on a high enough proportion of protein into the membranes. We propose that, in contrast to SP-B, membrane permeabilization by SP-C could be rather dependent on the deep perturbation of the membrane core by the protein. These profound perturbations could be also the cause of the extraordinarily dynamic behaviour imparted by SP-C into the membrane morphology, as we have observed in the GUVs fluctuations. The ability of SP-C to introduce a dynamic contribution into phospholipid membranes has been already outlined, in which the N-terminal, relatively polar, segment of the protein seems to have a significant participation $[35,36]$.

The present results strongly suggest that the combination of SP-B and SP-C impart special properties to membranes, which are clearly distinct to the effects of each individual protein by itself. Surfactant membranes are the most stable in the simultaneous presence of both SPB and SP-C, while the individual proteins seem to have apparently opposite destabilizing effects. SP-B alone promotes transformation of single vesicles into large, complex, presumably multilamellar, membrane structures. This ability of the protein to promote association and eventually fusion of membranes, with the important participation of proteinprotein interactions, has been in fact widely documented [9, 10, 26, 30, 37]. SP-C, by its side, seems to strongly destabilize bilayers, promoting their disintegration and dispersion. This activity could be behind the ability of the protein to promote insertion of phospholipids into the interface $[38,39]$. However, the incorporation of SP-B/SP-C complexes, with the precise protein stoichiometry obtained from the natural surfactant mixtures, maintains apparently the morphology of the lipid-protein membranes, at least in the context of the models studied here, suggesting that SP-B and SP-C might modulate each other. An obvious possibility is that the two proteins participate in common macromolecular protein complexes in the context of surfactant membranes. The differences in permeability induced upon introduction of single or combined proteins into giant liposomes are very illustrative. In the presence of SP-B/SP-C complexes, lipid membranes are permeable to calcein, which can permeate through pores of presumably limited size, considering that dilution of external calcein does not produce a concomitant immediate dilution of calcein from the internal liposome compartments. Equilibration of inner and outer calcein concentrations is much faster in GUVs containing either SP-B or SP-C, suggesting that the permeation structures assembled by a single protein permit a much rapid flow of the probe. Although recent results certainly suggest that a concerted action of the two proteins facilitates breathing dynamics in vivo [40], we and others have were unable to find evidences for specific SP-B/SP-C interactions [35]. In a recent study in which we have compared functional properties of systems prepared by reconstituting defined fractions of native surfactant, we have found that some differences exist between the behaviour of lipid/protein complexes prepared from the original mixtures and the behaviour of complexes reunited from isolated components [41]. It is possible that 
proper SP-B/SP-C complexes are poorly re-stablished once the proteins are re-mixed, perhaps because some unknown cofactors were lost, or because the proper conformation of the proteins is altered, during the purification process. Our present data suggest that much care has to be taken to dissect the potential role and the structure-function relationships of surfactant proteins upon reconstitution of simplified systems that start from fully purified SPB and SP-C. An unbalance in the appropriate SP-B/SP-C ratio or an inefficient re-assembly of potential multiprotein complexes, may end in lipid-protein membranes with structural and functional properties differing much of those exhibited by native surfactant membranes. The most successful clinical surfactant preparations currently in use for the treatment of respiratory pathologies are derived from extracts of animal-derived surfactants [42]. These natural formulations probably preserve a fair proportion of the original surfactant protein complexes. Design and production of a new generation of therapeutic surfactants, based on the reconstitution of synthetic or recombinant human versions of surfactant proteins, will require a proper knowledge of the role of protein complexes and the way these complexes can be correctly established.

An important question opened refers to the physiological meaning of the intrinsic permeable character of surfactant membranes. It is possible that the permeability to polar solutes imparted to membranes by the surfactant protein complexes is only a consequence of the architecture of the machinery that ensures a rapid and efficient flow of surface active lipid species along the membranous assemblies, all the way up to the interface. However, it is also possible that an efficient and unrestricted movement of polar molecules through the membrane structures developed by surfactant at the thin water layer lining the alveoli is also important for alveolar homeostasis. It has been recently proposed that surfactant might form a sort of "bi-continuous" membrane-based phase at the respiratory surface [7, 43]. A fully interconnected network of membranes could be important to facilitate a rapid diffusion of lipids towards the interface, where they must form the surface active film that reduces surface tension and stabilizes the lung. However, the continuity of all the aqueous compartments could be equally important to ensure proper equilibrium of water and ions and to facilitate free diffusion of soluble components such as many of those in charge of maintaining the sterility of the alveolar surface. Surface active proteins and peptides, such as those currently under scrutiny as potential additive in artificial surfactants [44], could be active enough to ensure interfacial transfer of lipids and formation of surfactant films but still be inefficient to form a fully functional bi-continuous membrane network. The elucidation of the molecular architecture and the determinants of potential surfactant protein complexes is therefore a must to improve the possibilities to develop new enhanced surfactant-based therapies.

\section{ACKNOWLEDGEMENTS}

This research has been supported by grants from the Spanish Ministry of Science (BIO200909694, FIS2009-14650-C02-01 and CONSOLIDER-INGENIO 2010 CSD2007-00010), Community of Madrid (S0505/MAT/0283) and Universidad Complutense. 


\section{REFERENCES}

1 Serrano, A. G. and Perez-Gil, J. (2006) Protein-lipid interactions and surface activity in the pulmonary surfactant system. Chem Phys Lipids. 141, 105-118

2 Wright, J. R. (2005) Immunoregulatory functions of surfactant proteins. Nat Rev Immunol. 5, 58-68

3 Seeger, W., Gunther, A., Walmrath, H. D., Grimminger, F. and Lasch, H. G. (1993) Alveolar surfactant and adult respiratory distress syndrome. Pathogenetic role and therapeutic prospects. Clin Investig. 71, 177-190

4 Hallman, M., Glumoff, V. and Ramet, M. (2001) Surfactant in respiratory distress syndrome and lung injury. Comp Biochem Physiol A Mol Integr Physiol. 129, 287-294

5 Goerke, J. (1998) Pulmonary surfactant: functions and molecular composition. Biochim Biophys Acta. 1408, 79-89

6 Veldhuizen, R., Nag, K., Orgeig, S. and Possmayer, F. (1998) The role of lipids in pulmonary surfactant. Biochim Biophys Acta. 1408, 90-108

7 Perez-Gil, J. (2008) Structure of pulmonary surfactant membranes and films: the role of proteins and lipid-protein interactions. Biochim Biophys Acta. 1778, 1676-1695

8 Melton, K. R., Nesslein, L. L., Ikegami, M., Tichelaar, J. W., Clark, J. C., Whitsett, J. A. and Weaver, T. E. (2003) SP-B deficiency causes respiratory failure in adult mice. Am J Physiol Lung Cell Mol Physiol. 285, L543-549

9 Ryan, M. A., Qi, X., Serrano, A. G., Ikegami, M., Perez-Gil, J., Johansson, J. and Weaver, T. E. (2005) Mapping and analysis of the lytic and fusogenic domains of surfactant protein B. Biochemistry. 44, 861-872

10 Cruz, A., Worthman, L. A., Serrano, A. G., Casals, C., Keough, K. M. and PerezGil, J. (2000) Microstructure and dynamic surface properties of surfactant protein SP$\mathrm{B} /$ dipalmitoylphosphatidylcholine interfacial films spread from lipid-protein bilayers. Eur Biophys J. 29, 204-213

11 Glasser, S. W., Burhans, M. S., Korfhagen, T. R., Na, C. L., Sly, P. D., Ross, G. F., Ikegami, M. and Whitsett, J. A. (2001) Altered stability of pulmonary surfactant in SP-Cdeficient mice. Proc Natl Acad Sci U S A. 98, 6366-6371

12 Creuwels, L. A., Boer, E. H., Demel, R. A., van Golde, L. M. and Haagsman, H. P. (1995) Neutralization of the positive charges of surfactant protein C. Effects on structure and function. J Biol Chem. 270, 16225-16229

13 Ross, M., Krol, S., Janshoff, A. and Galla, H. J. (2002) Kinetics of phospholipid insertion into monolayers containing the lung surfactant proteins SP-B or SP-C. Eur Biophys J. 31, 52-61

14 Weaver, T. E., Na, C. L. and Stahlman, M. (2002) Biogenesis of lamellar bodies, lysosome-related organelles involved in storage and secretion of pulmonary surfactant. Semin Cell Dev Biol. 13, 263-270

15 Bernardino de la Serna, J., Oradd, G., Bagatolli, L. A., Simonsen, A. C., Marsh, D., Lindblom, G. and Perez-Gil, J. (2009) Segregated phases in pulmonary surfactant membranes do not show coexistence of lipid populations with differentiated dynamic properties. Biophys J. 97, 1381-1389

16 Taeusch, H. W., de la Serna, J. B., Perez-Gil, J., Alonso, C. and Zasadzinski, J. A. (2005) Inactivation of pulmonary surfactant due to serum-inhibited adsorption and reversal by hydrophilic polymers: experimental. Biophys J. 89, 1769-1779

17 Perez-Gil, J., Cruz, A. and Casals, C. (1993) Solubility of hydrophobic surfactant proteins in organic solvent/water mixtures. Structural studies on SP-B and SP-C in aqueous organic solvents and lipids. Biochim Biophys Acta. 1168, 261-270 
18 Rouser, G., Siakotos, A. N. and Fleischer, S. (1966) Quantitative analysis of phospholipids by thin-layer chromatography and phosphorus analysis of spots. Lipids. 1, $85-86$

19 Mathivet, L., Cribier, S. and Devaux, P. F. (1996) Shape change and physical properties of giant phospholipid vesicles prepared in the presence of an AC electric field. Biophys J. 70, 1112-1121

20 Greenspan, P., Mayer, E. P. and Fowler, S. D. (1985) Nile red: a selective fluorescent stain for intracellular lipid droplets. J Cell Biol. 100, 965-973

21 Betz, W. J., Mao, F. and Smith, C. B. (1996) Imaging exocytosis and endocytosis. Curr Opin Neurobiol. 6, 365-371

22 Arrais, D. and Martins, J. (2007) Bilayer polarity and its thermal dependency in the 1(o) and 1(d) phases of binary phosphatidylcholine/cholesterol mixtures. Biochim Biophys Acta. 1768, 2914-2922

23 Theunissen, J. J., Jackson, R. L., Kempen, H. J. and Demel, R. A. (1986) Membrane properties of oxysterols. Interfacial orientation, influence on membrane permeability and redistribution between membranes. Biochim Biophys Acta. 860, 66-74

24 Bernardino de la Serna, J., Perez-Gil, J., Simonsen, A. C. and Bagatolli, L. A. (2004) Cholesterol rules: direct observation of the coexistence of two fluid phases in native pulmonary surfactant membranes at physiological temperatures. J Biol Chem. 279, 4071540722

25 Haller, T., Ortmayr, J., Friedrich, F., Volkl, H. and Dietl, P. (1998) Dynamics of surfactant release in alveolar type II cells. Proc Natl Acad Sci U S A. 95, 1579-1584

26 Chang, R., Nir, S. and Poulain, F. R. (1998) Analysis of binding and membrane destabilization of phospholipid membranes by surfactant apoprotein B. Biochim Biophys Acta. 1371, 254-264

27 Cruz, A., Casals, C., Keough, K. M. and Perez-Gil, J. (1997) Different modes of interaction of pulmonary surfactant protein SP-B in phosphatidylcholine bilayers. Biochem J. 327 ( Pt 1), 133-138

28 Shiffer, K., Hawgood, S., Duzgunes, N. and Goerke, J. (1988) Interactions of the low molecular weight group of surfactant-associated proteins (SP 5-18) with pulmonary surfactant lipids. Biochemistry. 27, 2689-2695

29 Perez-Gil, J., Casals, C. and Marsh, D. (1995) Interactions of hydrophobic lung surfactant proteins SP-B and SP-C with dipalmitoylphosphatidylcholine and dipalmitoylphosphatidylglycerol bilayers studied by electron spin resonance spectroscopy. Biochemistry. 34, 3964-3971

30 Poulain, F. R., Nir, S. and Hawgood, S. (1996) Kinetics of phospholipid membrane fusion induced by surfactant apoproteins A and B. Biochim Biophys Acta. 1278, 169-175

31 Oelberg, D. G. and Xu, F. (2000) Pulmonary surfactant proteins insert cationpermeable channels in planar bilayers. Mol Genet Metab. 70, 295-300

32 Leippe, M., Bruhn, H., Hecht, O. and Grotzinger, J. (2005) Ancient weapons: the three-dimensional structure of amoebapore A. Trends Parasitol. 21, 5-7

33 Miteva, M., Andersson, M., Karshikoff, A. and Otting, G. (1999) Molecular electroporation: a unifying concept for the description of membrane pore formation by antibacterial peptides, exemplified with NK-lysin. FEBS Lett. 462, 155-158

34 Patthy, L. (1991) Homology of the precursor of pulmonary surfactant-associated protein SP-B with prosaposin and sulfated glycoprotein 1. J Biol Chem. 266, 6035-6037

35 Plasencia, I., Cruz, A., Casals, C. and Perez-Gil, J. (2001) Superficial disposition of the N-terminal region of the surfactant protein SP-C and the absence of specific SP-B-SP$\mathrm{C}$ interactions in phospholipid bilayers. Biochem J. 359, 651-659 
36 Plasencia, I., Rivas, L., Keough, K. M., Marsh, D. and Perez-Gil, J. (2004) The Nterminal segment of pulmonary surfactant lipopeptide SP-C has intrinsic propensity to interact with and perturb phospholipid bilayers. Biochem J. 377, 183-193

37 Poulain, F. R., Allen, L., Williams, M. C., Hamilton, R. L. and Hawgood, S. (1992) Effects of surfactant apolipoproteins on liposome structure: implications for tubular myelin formation. Am J Physiol. 262, L730-739

38 Oosterlaken-Dijksterhuis, M. A., Haagsman, H. P., van Golde, L. M. and Demel, R. A. (1991) Characterization of lipid insertion into monomolecular layers mediated by lung surfactant proteins SP-B and SP-C. Biochemistry. 30, 10965-10971

39 Perez-Gil, J., Tucker, J., Simatos, G. and Keough, K. M. (1992) Interfacial adsorption of simple lipid mixtures combined with hydrophobic surfactant protein from pig lung. Biochem Cell Biol. 70, 332-338

40 Almlen, A., Stichtenoth, G., Linderholm, B., Haegerstrand-Bjorkman, M., Robertson, B., Johansson, J. and Curstedt, T. (2008) Surfactant proteins B and C are both necessary for alveolar stability at end expiration in premature rabbits with respiratory distress syndrome. J Appl Physiol. 104, 1101-1108

41 Schurch, D., Ospina, O. L., Cruz, A. and Perez-Gil, J. (2010) Combined and independent action of proteins SP-B and SP-C in the surface behavior and mechanical stability of pulmonary surfactant films. Biophys J. 99, 3290-3299

42 Blanco, O. and Perez-Gil, J. (2007) Biochemical and pharmacological differences between preparations of exogenous natural surfactant used to treat Respiratory Distress Syndrome: role of the different components in an efficient pulmonary surfactant. Eur J Pharmacol. 568, 1-15

43 Perez-Gil, J. and Weaver, T. E. (2010) Pulmonary surfactant pathophysiology: current models and open questions. Physiology (Bethesda). 25, 132-141

44 Mingarro, I., Lukovic, D., Vilar, M. and Perez-Gil, J. (2008) Synthetic pulmonary surfactant preparations: new developments and future trends. Curr Med Chem. 15, 393-403 


\section{LEGEND TO FIGURES}

Fig. 1. Dependence of Nile Red and FM 1-43 $(1 \mu \mathrm{g} / \mathrm{ml})$ fluorescent emission on phospholipid concentration in different materials. All values have been normalized, being $\mathrm{F}_{0}$ the maximum emission of each probe corresponding to the highest phospholipid concentration tested: 700 $\mu \mathrm{g} / \mathrm{ml}$ in the case of Nile Red and $350 \mu \mathrm{g} / \mathrm{ml}$ for FM 1-43 .

Fig. 2: Comparison between unilamellar and multilamellar systems for native pulmonary surfactant, organic extract and POPC. The reference value $\mathrm{F}_{0}$ is specific for each material, corresponding to the emission of FM 1-43 in the multilamellar sample with the highest lipid concentration tested.

Fig. 3: Comparison between unilamellar and multilamellar systems for model membranes of $\widehat{\text { POPC }}$ and membranes of POPC supplemented with the hydrophobic protein fraction, $1 \%$ $(\mathrm{w} / \mathrm{w})$ SP-B and $1 \%(\mathrm{w} / \mathrm{w})$ SP-C. The reference value $\mathrm{F}_{0}$ is specific for each material, corresponding to the emission of FM 1-43 in the pure POPC sample with the highest lipid concentration tested.

Fig. 4: Kinetic studies of the incorporation of FM 1-43 to multilamellar vesicles of POPC supplemented with different percentages (w/w P/L) of SP-B and SP-C. Results correspond to three different phospholipids concentrations: $50(\boldsymbol{O}), 200(\nabla)$ and $400 \mu \mathrm{g} / \mathrm{ml}(\mathbf{\square})$.

Kinetic studies of the incorporation of FM 1-43 to multilamellar vesicles of POPC supplemented with different percentages (by weight of phospholipids) of SP-B and SP-C. Results are shown in comparison with the control sample, MLV of pure POPC.

Fig. 5: Fluorescence emission of the probe FM 1-43 in POPC multilamelar vesicles (200 $\mu \mathrm{g} / \mathrm{ml}$ ) as a function of protein density in membranes.

Fig. 6: Electron microscopy images of vesicle suspensions prepared by extrusion, which correspond to different lipid-protein composition: POPC (image A), POPC supplemented with the hydrophobic protein fraction of pulmonary surfactant (B), with $1 \%$ SP-B (C) and 1\% SP-C (D) by weight of phospholipids. Samples were prepared by negative staining.

Fig. 7: Giant oligolamellar vesicles of POPC (A-D) and POPC supplemented with the hydrophobic protein fraction of pulmonary surfactant $(\mathrm{E}-\mathrm{H})$. A, C, E and G are transmission images; B, D, F and H, fluorescent images. All the giant vesicles are labelled with FM 1-43 . Scale bars correspond to $10 \mu \mathrm{m}$.

Fig. 8: Giant oligolamellar vesicles of POPC supplemented with 1\% (w/w) SP-B (images AD) and $1 \%(\mathrm{w} / \mathrm{w})$ SP-C $(\mathrm{E}-\mathrm{H}) . \mathrm{A}, \mathrm{C}, \mathrm{E}$ and $\mathrm{G}$ are transmission images; B, D, F and H, fluorescent images. Giant vesicles are labelled with FM 1-43. Scale bars: $10 \mu \mathrm{m}$.

Fig. 9: Image sequence extracted from a video recording. Giant vesicles of POPC supplemented with $1 \%(\mathrm{w} / \mathrm{w})$ SP-C became very unstable and dynamic when observed under the microscope; even exocytotic-like processes were seen. The complete recording is available on Additional Material section. Scale bar: $20 \mu \mathrm{m}$.

Fig. 10: Giant vesicles of POPC (first row), POPC supplemented with the hydrophobic protein fraction of pulmonary surfactant (second row), with $1 \%(\mathrm{w} / \mathrm{w})$ SP-B (third row) and 
$1 \%(\mathrm{w} / \mathrm{w})$ SP-C (fourth row). The first column corresponds to transmission images; the second and the third columns, to fluorescent images obtained with FITC and Texas Red filter sets, respectively. Giant vesicles were incubated in a calcein solution for several hours, then diluted in a glucose solution and finally labelled with FM 1-43 prior to the observation. See Experimental section for details. 


\section{Figure 1}

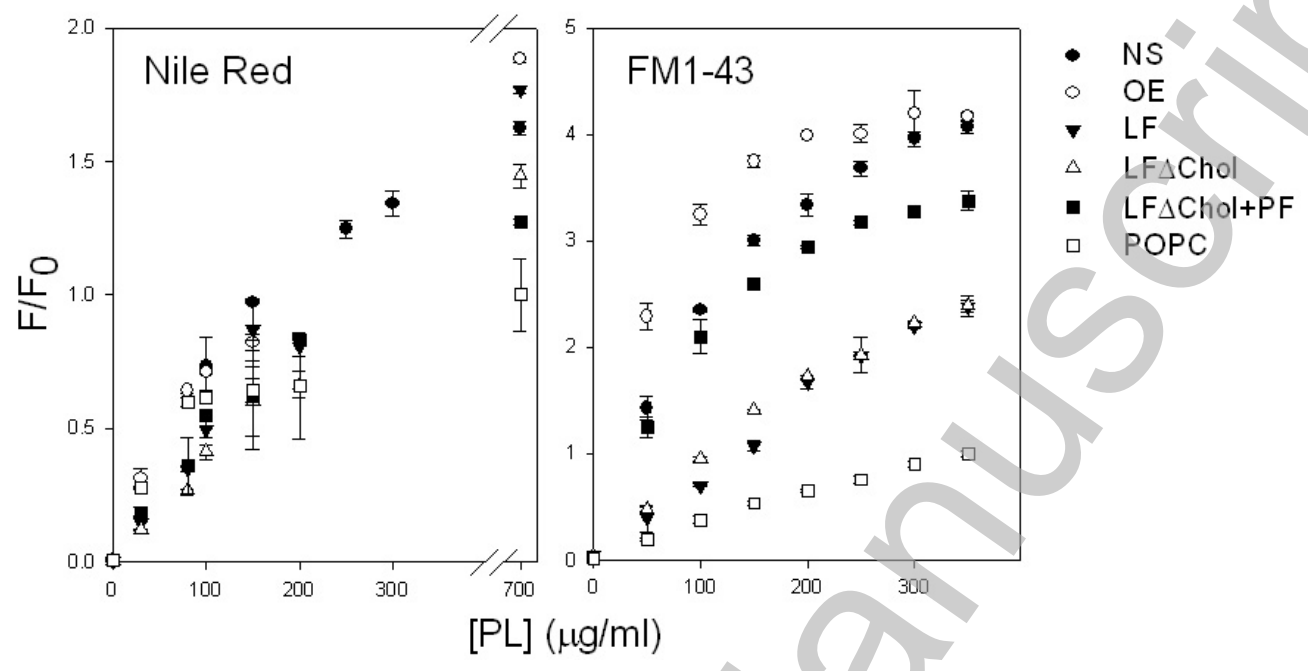




\section{Figure 2}

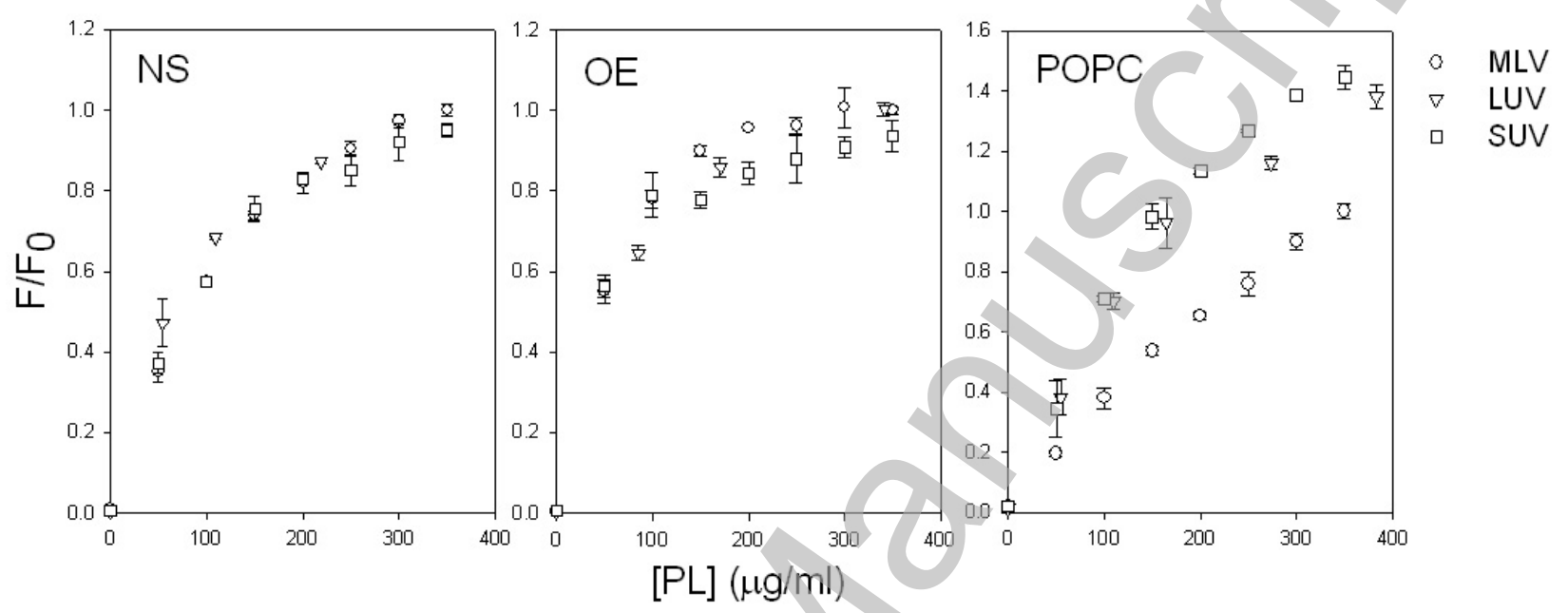




\section{Figure 3}

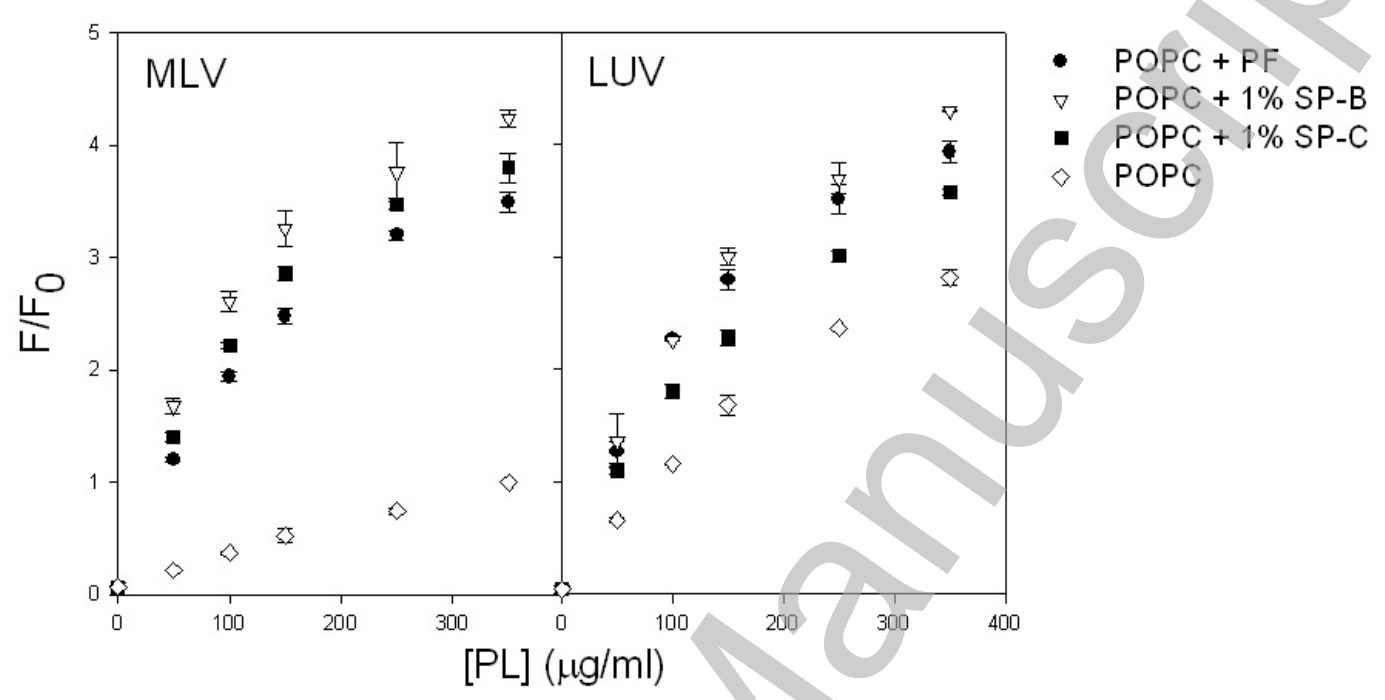




\section{Figure 4}

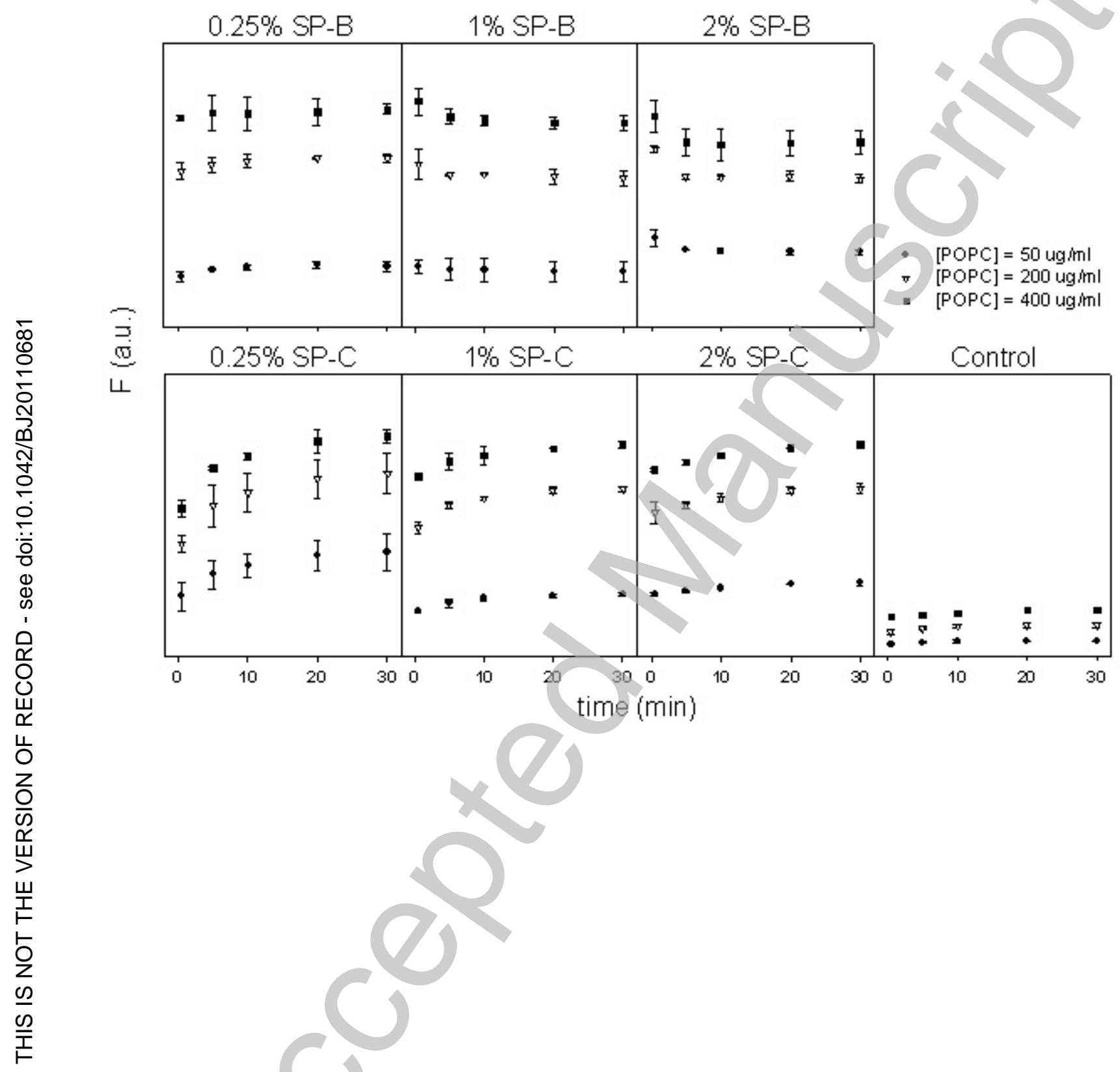




\section{Figure 5}

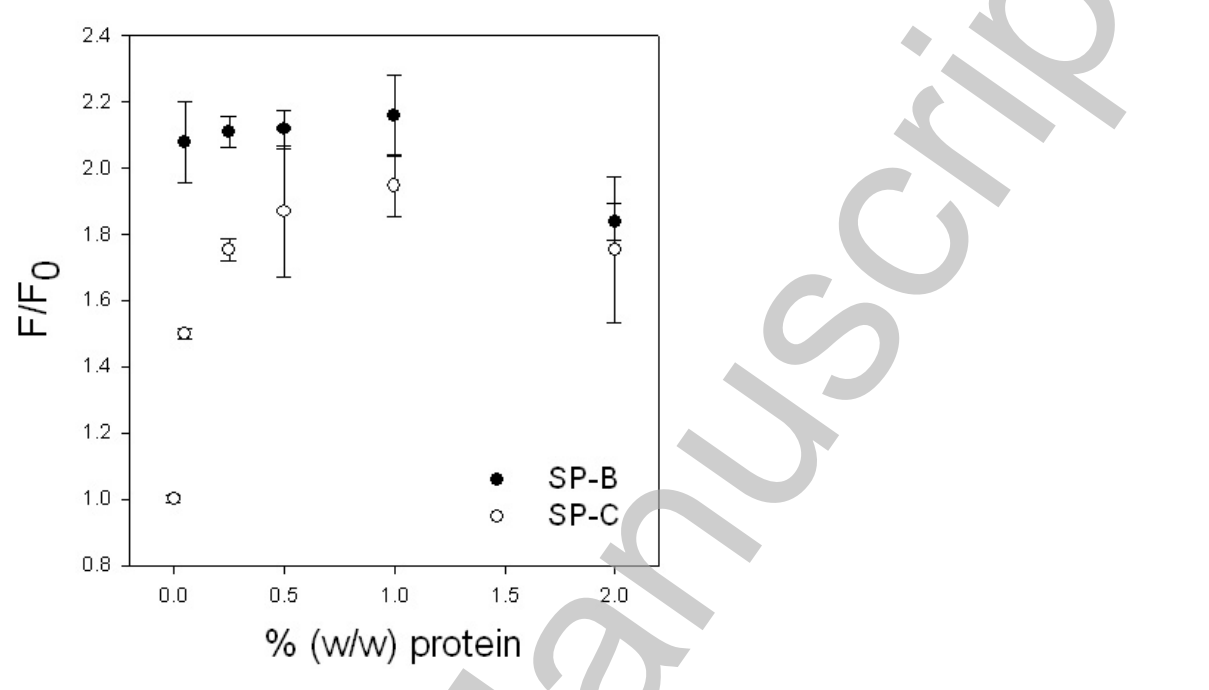


B) Biochemical Journal Immediate Publication. Published on 16 Jun 2011 as manuscript BJ20110681

\section{Figure 6}
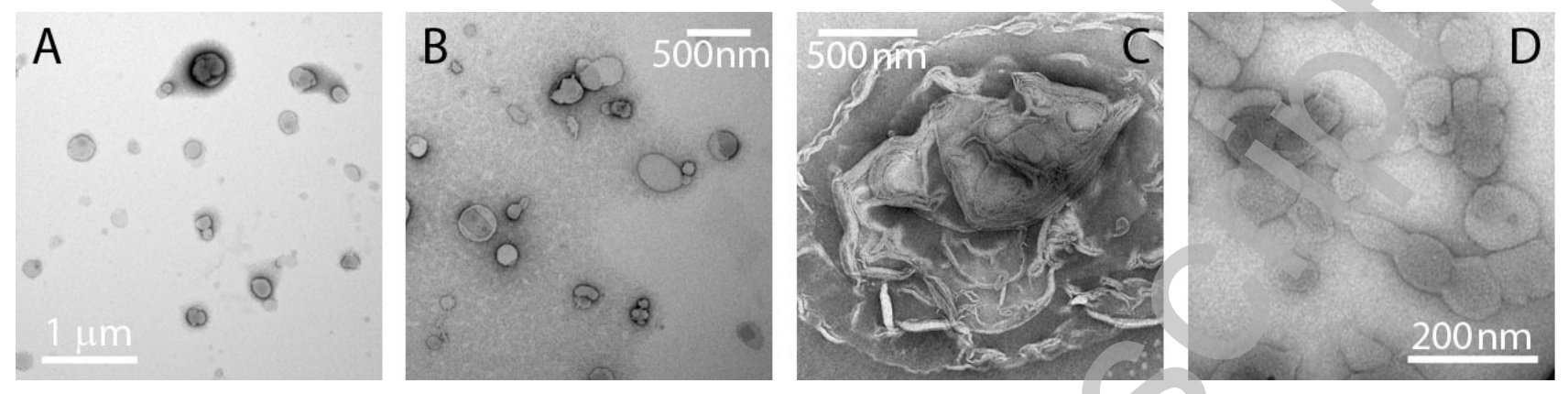

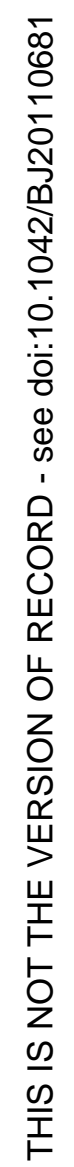




\section{Figure 7}

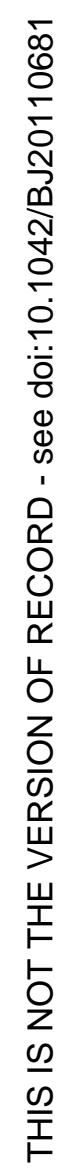

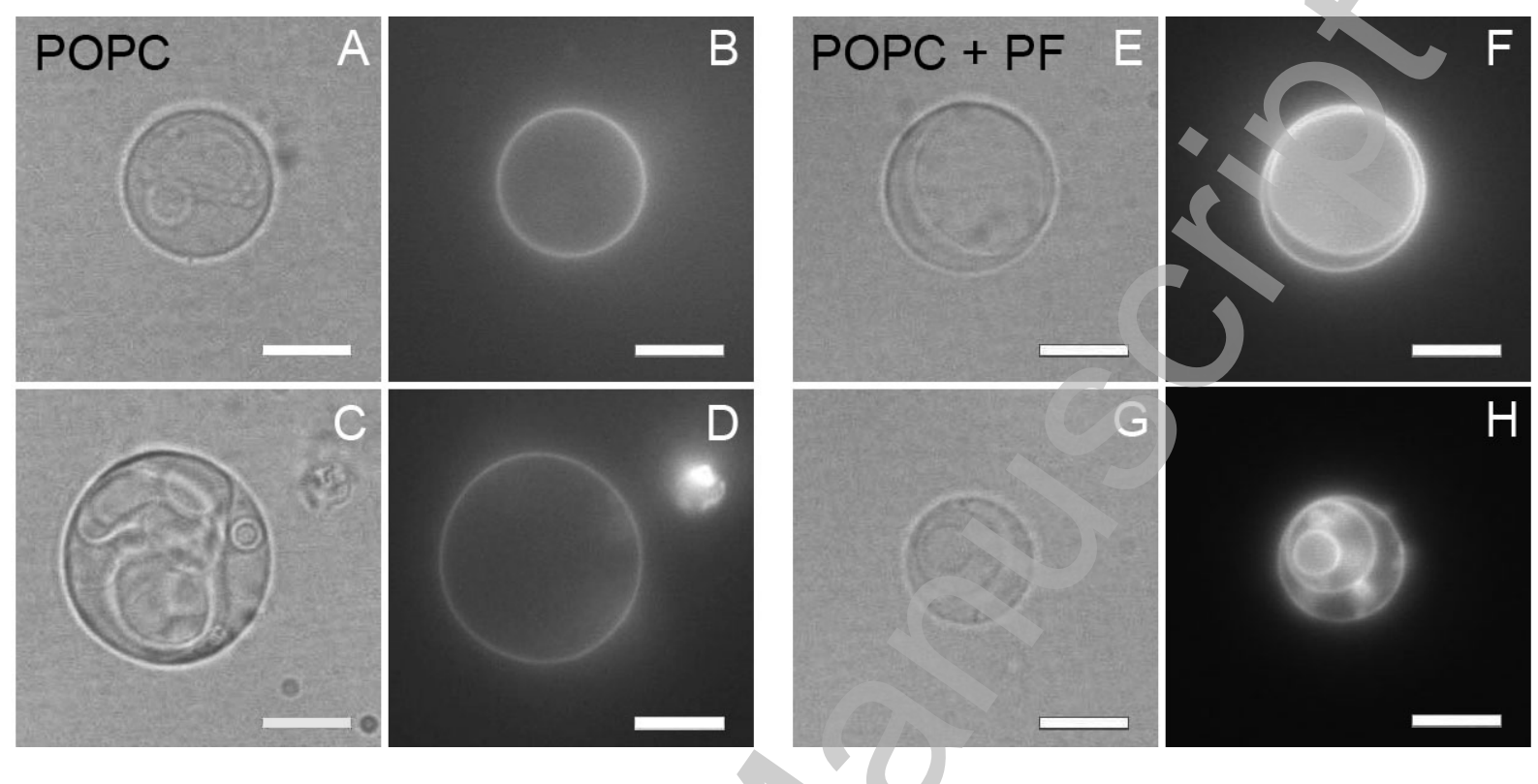


Biochemical Journal Immediate Publication. Published on 16 Jun 2011 as manuscript BJ20110681

\section{Figure 8}

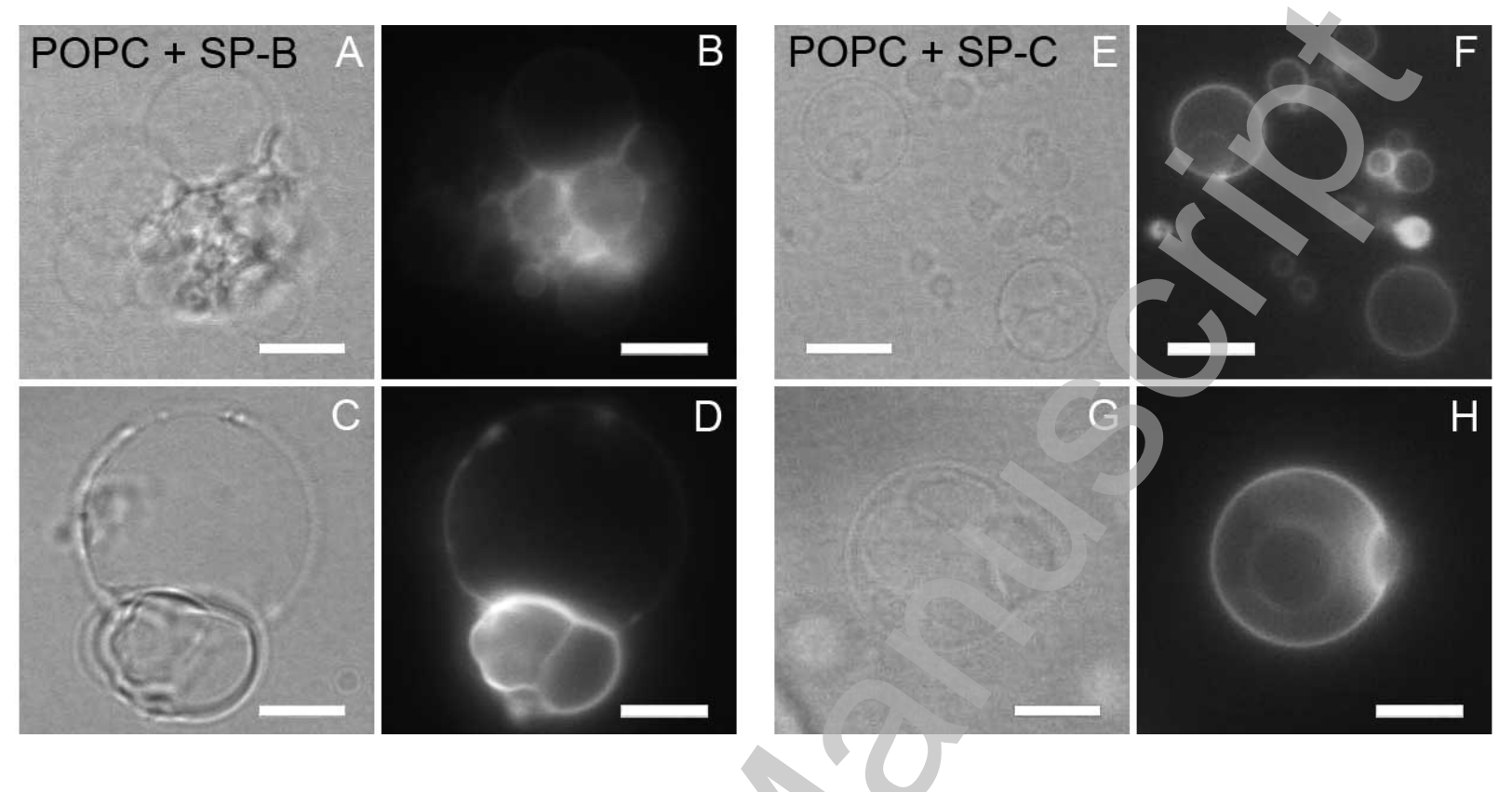

Licenced copy. Copying is not permitted, except with prior permission and as allowed by law. (c) 2011 The Authors Journal compilation (c) 2011 Portland Press Limited 


\section{Figure 9}
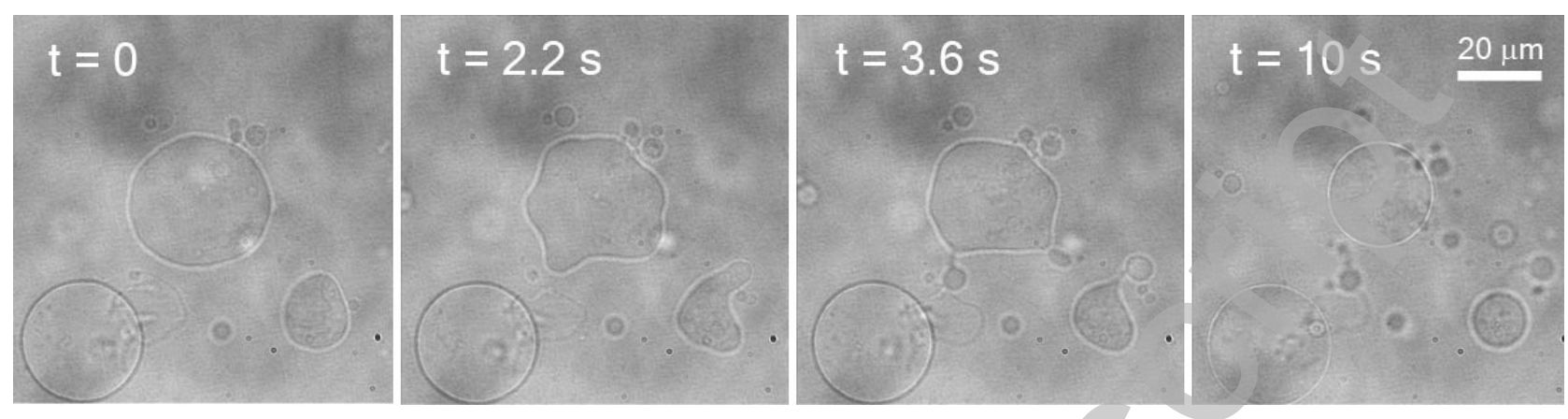

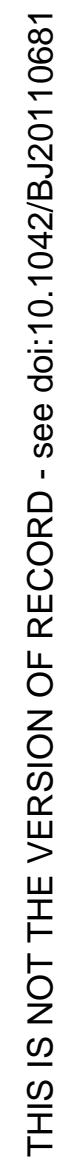


B) Biochemical Journal Immediate Publication. Published on 16 Jun 2011 as manuscript BJ20110681

\section{Figure 10}

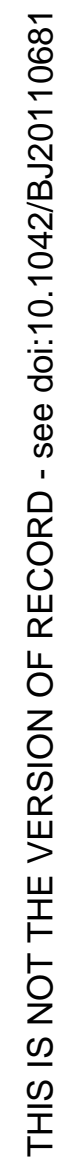

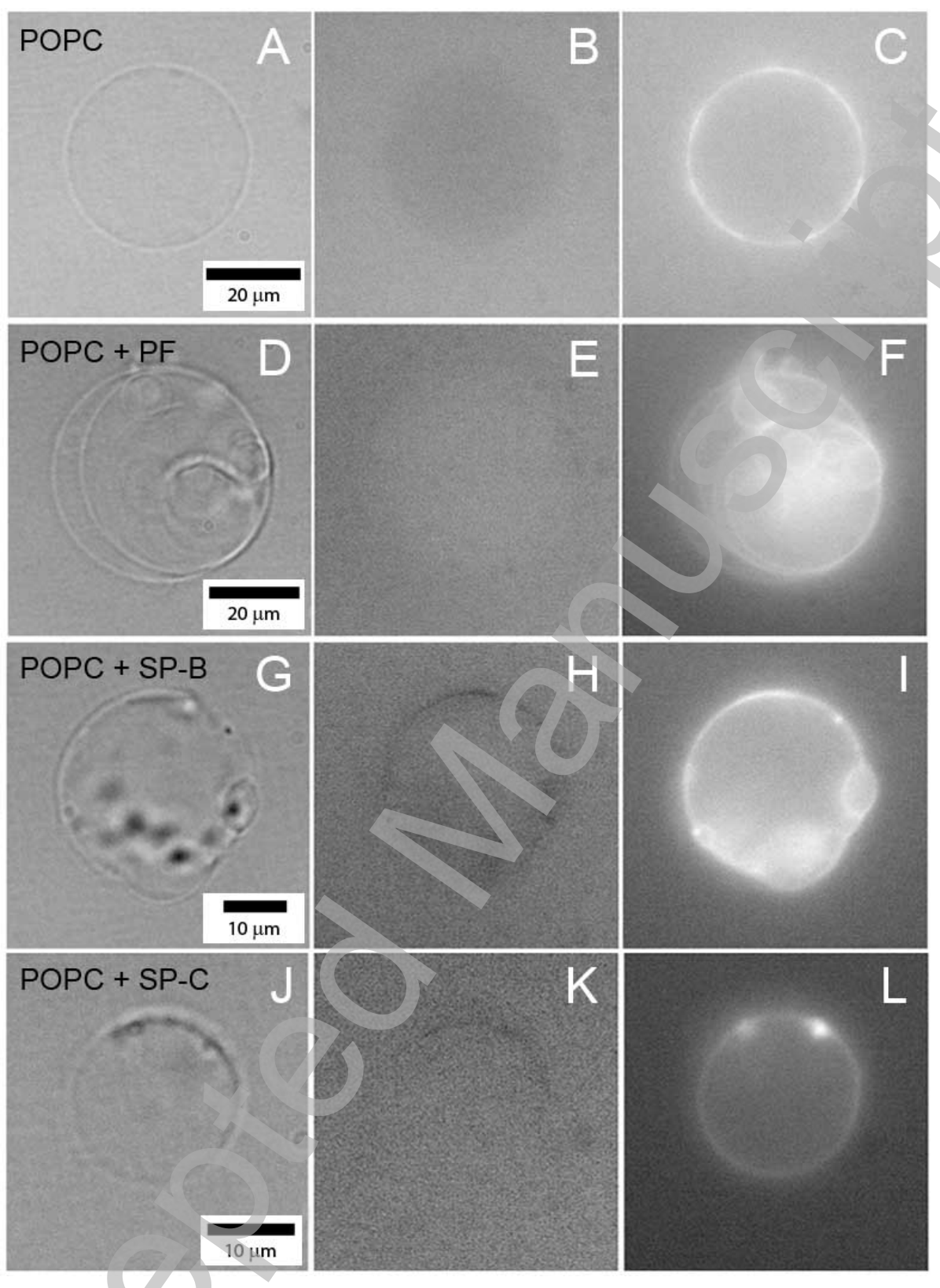

